noteworthy, especially since this drug has for so long been regarded as the treatment of choice in rheumatoid arthritis. Almost half of the patients failed to continue aspirin therapy for six months and the remainder were able to take on average only $4 \mathrm{~g}$ daily. Even with this dose almost half of the patients continued to have tinnitus or deafness. By contrast gastrointestinal side effects did not persist throughout the six months of the trial, probably because patients could not tolerate such side effects and either dropped out or reduced the dose.

We are indebted to Dr. Enid Taylor and Mr. I. Duiguid, who carried out the ophthalmic examinations, and to Dista Products Ltd., for supply of materials and for their co-operation in the study.

\section{References} Boardman, P. L., and Hart, F. D. (1967). British Medical fournal, 4, 264.
Chernish, S. M., Rubin, A., Rodda, B. E., Ridolfo, A. S., and Gruber, C. M. (1972). Clinical Pharmacology and Therapeutics, 14, 226.

Gruber, C. M., and Collins, T. (1972). Fournal of Medicine, 3, 242

Huskisson, E. C., Hart, F. D., Shenfield, G. M., and Taylor, R. T. (1971) Practitioner, 207, 639 .

Nickander, R. C., Kroay, R. J., and Marshall, W. S. (1971). Federation Proceedings, 30, 563 .

Ridolfo, A. S., Rubin, A., Crabtree, R. E., and Gruber, C. M. (1973). Clinical Pharmacology and Therapeutics, 14, 226.

Ritchie, D. M., et al. (1968). Quarterly fournal of Medicine, 37, 393.

Rubin, A., et al. (1972). Fournal of Pharmacology and Experimental Therapeutics, 13, 151 .

Sunshine, A., and Laska, E. (1971). Clinical Pharmacology and Therapeutics, 12,302 .

\title{
Penicillamine in Rheumatoid Disease: A Long-term Study
}

\author{
ALBERT T. DAY, JOHN R. GOLDING, PETER N. LEE, ANN D. BUTTERWORTH
}

British Medical fournal, 1974, 1, 180-183

\section{Summary}

Eighty-five patients with rheumatoid disease were treated with penicillamine, and 69 completed more than one year's treatment. The main reason for discontinuing penicillamine in the 16 patients who withdrew was adverse reaction. The number of adverse reactions, however, declined when patients were given lower maintenance doses of penicillamine. In those who tolerated the drug the results of treatment were good. To prevent side effects the drug should be introduced gradually and maintenance doses should be the lowest which produce a satisfactory response. Urine should be monitored for protein and blood for changes in platelet and white cell counts at frequent intervals throughout treatment.

\section{Introduction}

We began a study of penicillamine therapy in rheumatoid disease in 1967, encouraged by reports from the U.S.A. (Jaffe, 1963). When we found that our preliminary results were in general agreement with those of Jaffe (Golding et al., 1968; 1970) a multicentre controlled trial was conducted (Multicentre Trial Group, 1973). We here report on the further progress of the original group of patients, some of whom have now completed five years of treatment. This is the largest recorded series of patients with the longest period of follow-up, and from it we have concluded that smaller doses of penicillamine than are usually advocated are often effective and cause fewer adverse reactions-a matter of some consequence now that the drug is being more widely prescribed.

\section{Patients and Methods}

All the patients admitted to the study had "definite" or

Royal Bath Hospital, Harrogate, Yorkshire

ALBERT T. DAY, M.B., M.R.c.G.P., General Practitioner, Clinical and

Research Assistant
JOHN R. GOLDING, D.M., M.R.C.P., Consultant Physician

PETER N. LEE, M.A., Consultant Statistician

ANN D. BUTTERWORTH, B.SC., Consultant Statistician "classical" rheumatoid arthritis according to American Rheumatism Association criteria and had had laboratory and clinical evidence of active disease for at least a year. All were attending the Royal Bath Hospital, Harrogate. Their progress was assessed monthly by the following indices: (1) erythrocyte sedimentation rate (Westergren); (2) haemoglobin; (3) sheep cell agglutination test; (4) latex fixation test; (5) duration of morning stiffness (hours); (6) weight; and (7) an observer assessment of the patient's improvement during the previous year, expressed as an integer in a range of -4 to +4 (no change $=0$ ).

Dosage.-Penicillamine was given as $150-\mathrm{mg}$ capsules of penicillamine hydrochloride or as $250-\mathrm{mg}$ tablets of penicillamine base (Distamine). An initial four capsules daily was rapidly increased to 16 (or eight tablets). The incidence of side effects, both major and minor, was such that we later adopted Jaffe's (1968) recommendation of beginning with not more than two capsules and slowly increasing the dose. More recently the starting dose has been $150 \mathrm{mg}$ daily and the maintenance dose has been kept as low as the disease response allowed-often a dose of $300-600 \mathrm{mg}$ is enough. The use of this low-dose regimen has apparently eliminated the serious blood changes seen previously.

Concomitant Therapy.-All of the patients were receiving anti-inflammatory drugs at the beginning of the study and many were on corticosteroid therapy. The latter was slowly withdrawn to conform to a maximum daily dose of $7.5 \mathrm{mg}$, then further reductions were made as the disease improved. Short courses of prednisolone were given for any acute flare-up. The amount of anti-inflammatory agent given varied, and phenylbutazone was withdrawn because of possible confusion in the interpretation of side effects. Indomethacin, $50-75 \mathrm{mg}$ nightly, was given to overcome morning stiffness but was withdrawn when possible. Intra-articular injections and physiotherapy were prescribed at the clinician's discretion. Copper sulphate solution $(0.1 \%)$ $5 \mathrm{ml}$ was given daily. Pyridoxine was not given.

\section{Results}

Between January 1967 and May 197385 patients had been given penicillamine and 69 had taken it for a year or more. The other 16 patients failed to complete one year's treatment for various reasons (table I). Of the 69 who took the drug for a year or more 24 took it for one full year, 14 for two years, 14 for three years, 14 for four years, and three for five years. Forty-five of the 69 patients are still taking penicillamine; the remaining 24 discontinued it for various reasons (table II). 
TABLE I-Reasons for Withdrawal of Penicillamine in 16 Patients who Completed less than 12 Months' Treatment

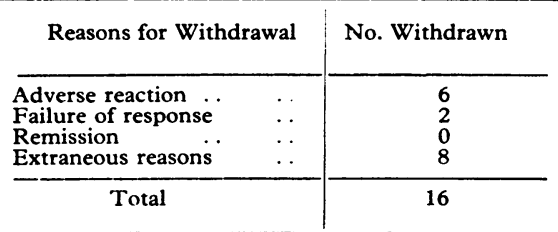

TABLE II-Reasons for Withdrawal of Penicillamine in 24 Patients who Completed at least 12 Months' Treatment and who later Withdrew

\begin{tabular}{|c|c|}
\hline Reasons for Withdrawal & No. Withdrawn \\
\hline $\begin{array}{l}\text { Adverse reaction ... } \\
\text { Failure of response } \\
\text { Remission (for } 3 \text { months) } \\
\text { Extraneous reasons }\end{array}$ & $\begin{array}{r}16 \\
6 \\
1 \\
1\end{array}$ \\
\hline Total & 24 \\
\hline
\end{tabular}

\section{THERAPEUTIC RESPONSE}

As a group, the patients who were able to tolerate pencillamine have done well. Since most of the benefit from the drug seemed to occur in the first year of treatment, and because the dose received by a patient often varied from year to year, we decided to consider each successive treatment year separately when analyzing the results. The response varied considerably, some patients doing very well and others making no appreciable progress, regardless of dose.

The change in each of the seven indices by which progress was assessed was calculated for each patient for each year of treatment and was related to the following variables. (a) Average dose of penicillamine received during the year measured in $\mathrm{mg}$. This was subsequently allotted to one of five dose groupsnamely, $150-450 \mathrm{mg}, 450-600 \mathrm{mg}, 600-900 \mathrm{mg}, 900-1,200 \mathrm{mg}$, and 1,200-1,800 mg. (b) "Initial value" of the index-that is, its value at the beginning of the year. This was subsequently allotted to one of several initial value groups. (c) Age of the patient at the beginning of the year. $(d)$ "Experience" of the patient-that is, the number of years the patient had suffered from rheumatoid arthritis at the beginning of the year.

Correlation coefficients were calculated within various dose $\times$ initial value subsets of patients to determine whether there was any relation between the changes in index values and the age or experience of a patient. The design of the experiment made more sophisticated tests undesirable. The method was adequate, however, to show that the age or experience of a patient had little or no effect on his or her response to penicillamine. Oneway analyses of variance showed that the different doses were evenly distributed over patients with different initial values of the indices. Thus, though the experiment was unbalanced in design, and the effect of any one explanatory variable could never theoretically be completely divorced from effects of the others, it seemed safe in practice to carry it out.

Preliminary analysis indicated that the initial value of an index had a considerable effect on its change; this was therefore corrected when considering the effect of dose. The correction was performed by subtracting from each change in a given index the average change associated with the initial value of that index in the given year. For each index and each treatment year oneway analyses of variance were carried out to determine whether there was: (a) a significant overall change in the index, (b) a significant difference between the effects of different initial value levels of the index, or (c) a significant difference between the effects of the five different dose levels.

To save space the detailed statistics are not given in the tables of results, except those covering the first full treatment year. Trends appearing in subsequent years are indicated. Detailed statistics will be supplied on request to those interested.
Haemoglobin.-The figures analysed were the (positive) changes in haemoglobin, and though an increase to a value of $100 \%$ or less is considered $\mathrm{si}$ improvement an increase beyond that point is a "deterioration." Similarly, a decrease from a value above $100 \%$ is an "improvement" so long as it does not bring the value below $100 \%$. Patients whose haemoglobin increased from below $100 \%$ to above it and those whose haemoglobin decreased from above $100 \%$ to below it more or less compensated for one another, however, and an analysis based on the change in proximity to the $100 \%$ value would probably not have altered the conclusions. In the first year there was a considerable overall improvement, especially among those patients with a very low initial reading. The dose effect was not significant but a higher dose tended to have a slightly better effect (tables III, IV, and V). In the second year more of the patients with low haemoglobin values improved but the overall change was not significant. By the end of the third year all of the patients had a level above $80 \%$.

Erythrocyte Sedimentation Rate.-In the first year there was a pronounced improvement among patients with an initial abnormal E.S.R. Doses of $50-450 \mathrm{mg}$ had a comparatively smaller effect and doses of $600-900 \mathrm{mg}$ a comparatively larger one (tables III, IV, and V). The E.S.R. tended slightly to deteriorate in the second year but not significantly, nor was there any difference between the doses. In subsequent years there was again neither a significant overall change nor a significant difference between doses.

Latex Slide Test.-In the first year there was a considerable overall improvement and though there was no significant differences between doses the $900 \mathrm{mg}$ dose was relatively more efficient than the rest (tables III, IV, and V). In subsequent years there was very little overall change.

Differential Agglutination Test.-In the first year nearly all the patients with abnormal differential agglutination improved significantly. The improvement of abnormal patients continued to a lesser extent during the second year, but little change occurred after that. There was little or no difference between doses in any year (tables III, IV, and V).

Weight.-The overall weight increased significantly during the first year, decreased significantly during the third year, and did not change at other times. The doses did not differ significantly in any year, but the results in the $600-900 \mathrm{mg}$ range were consistently better than average (tables III and VI).

Duration of Morning Stiffness.-In the first year there was a pronounced overall improvement, and the worse the patient the greater the improvement. Doses in the $600-900 \mathrm{mg}$ range were comparatively more effective, and $150-450 \mathrm{mg}$ doses less so (tables III, IV, and V). In subsequent years the improvement continued for those patients with morning stiffness of more than an hour. For all others the overall change was negligible and there was no consistent difference between doses.

TABLE III-Overall Change in all Indices at End of First Year of Treatment in 69 Patients

\begin{tabular}{|c|c|c|c|}
\hline Indices & & Mean \pm S.E. & $\mathbf{P}$ \\
\hline $\begin{array}{l}\text { Haemoglobin (\%) } \\
\text { E.S.R. (mm/hr) } \ldots \\
\text { Latex } \\
\text { Differential agglutination } \\
\text { Weight (lbs) } \\
\text { Morning stiffness (hrs) } \\
\text { Observer assessment }\end{array}$ & $\begin{array}{l}\cdots \\
\cdots \\
\cdots \\
\cdots \\
\cdots\end{array}$ & $\begin{array}{l}7.3 \pm 1.3 \\
-20.3 \pm 4.1 \\
-0.26 \pm 0.06 \\
-2.2 \pm 0.3 \\
2.2 \pm 1.1 \\
-1.42 \pm 0.13 \\
1.39 \pm 0.13\end{array}$ & $\begin{array}{l}<0.001 \\
<0.001 \\
<0.001 \\
<0.001 \\
<0.05 \\
<0.001 \\
<0.001\end{array}$ \\
\hline
\end{tabular}

Observer Assessment. - There was a highly significant overall improvement during the first year; this remained significant during the second year and was maintained, though not at a significant level, until the end of the fourth year. Throughout the first four years the $600-900 \mathrm{mg}$ dose was more effective than average (tables III and VII). 
TABLE IV-Change in Five Indices in 69 Patients at End of First Year of Treatment in Relation to Initial Value Levels

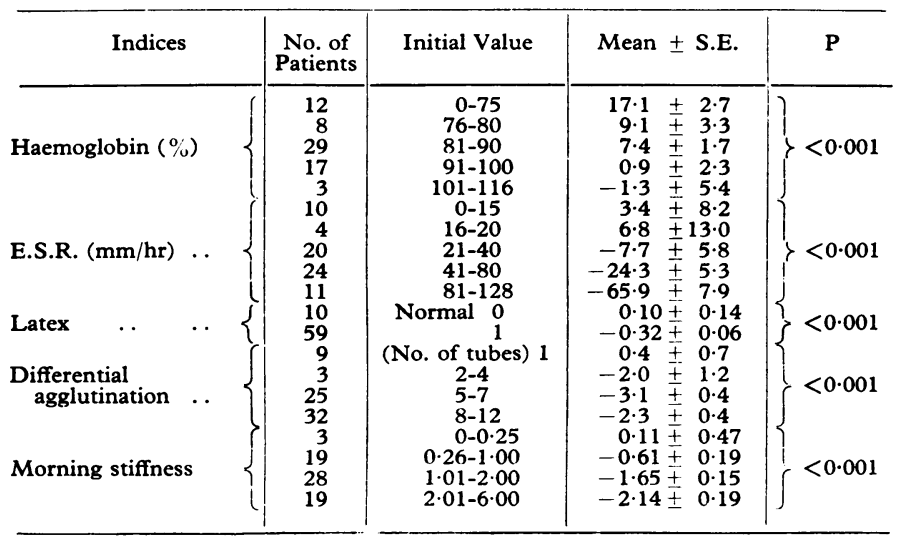

TABLE VI-Changes in Weight Additional to Average Change in 69 Patients at End of First Year of Treatment Related to Dosages

\begin{tabular}{l|c|c|c|c|c|c}
\hline $\begin{array}{l}\text { Dose of } \\
\text { penicillamine (mg) }\end{array}$ & $150-450$ & -600 & -900 & $-1,200$ & $-1,800$ & $P_{3}^{*}$ \\
$\begin{array}{l}\text { No. of patients } \\
\text { Mean } \pm \text { S.E. }\end{array}$ & $\cdots$ & 12 & 15 & 18 & 21 & 3 \\
\hline
\end{tabular}

*See text for definition.

TABLE VII-Observer Assessment Improvements Additional to Average Improvement in 69 Patients at End of First Year of Treatwent Related to Dosages

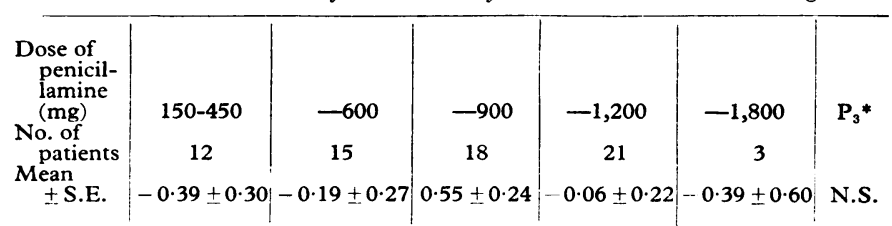

*See text for definition.

TABLE v-Change in Five Indices in 69 Patients at End of First Year of Treatment, Additional to that Related to Initial Value

\begin{tabular}{|c|c|c|c|c|c|c|}
\hline \multirow{2}{*}{ No. of Patients } & \multirow{2}{*}{ Dose (mg) } & \multicolumn{5}{|c|}{ Mean \pm S.E. } \\
\hline & & Haemoglobin $(\%)$ & E.S.R. $\mathrm{mm} / \mathrm{hr}$ & Latex & Differential Agglutination & Morning Stiffness \\
\hline \multirow[t]{2}{*}{$\begin{array}{r}12 \\
15 \\
18 \\
21 \\
3\end{array}$} & $\begin{array}{l}150-450 \\
-600 \\
-900 \\
-1200 \\
-1800\end{array}$ & $\begin{array}{r}-3.0 \pm 2.6 \\
-3.0 \pm 2.3 \\
2.2 \pm 2.1 \\
1.3 \pm 2.0 \\
5.1 \pm 5.2\end{array}$ & $\begin{aligned} & 19.4 \pm 6.8 \\
& 6.8 \pm 6.0 \\
&-12.5 \pm 5.5 \\
&-5.0 \pm 5.1 \\
&-1.8 \pm 13.5\end{aligned}$ & $\begin{array}{r}0.12 \pm 0.13 \\
-0.06 \pm 0.11 \\
-0.17 \pm 0.10 \\
0.14 \pm 0.10 \\
-0.15 \pm 0.26\end{array}$ & $\begin{array}{r}0.4 \pm 0.6 \\
0.4 \pm 0.5 \\
-0.5 \pm 0.5 \\
0.1 \pm 0.5 \\
-1.0 \pm 1.2\end{array}$ & $\begin{array}{r}0.61 \pm 0.22 \\
-0.03 \pm 0.19 \\
-0.37 \pm 0.18 \\
-0.03 \pm 0.16 \\
0.15 \pm 0.44\end{array}$ \\
\hline & $\mathbf{P}$ & N.S. & $<0.01$ & N.S. & N.S. & $<0.05$ \\
\hline
\end{tabular}

TABLE viII-Effects of Reducing Mean Daily Dose of Penicillamine on Side Effects and Withdrawals 1967-73

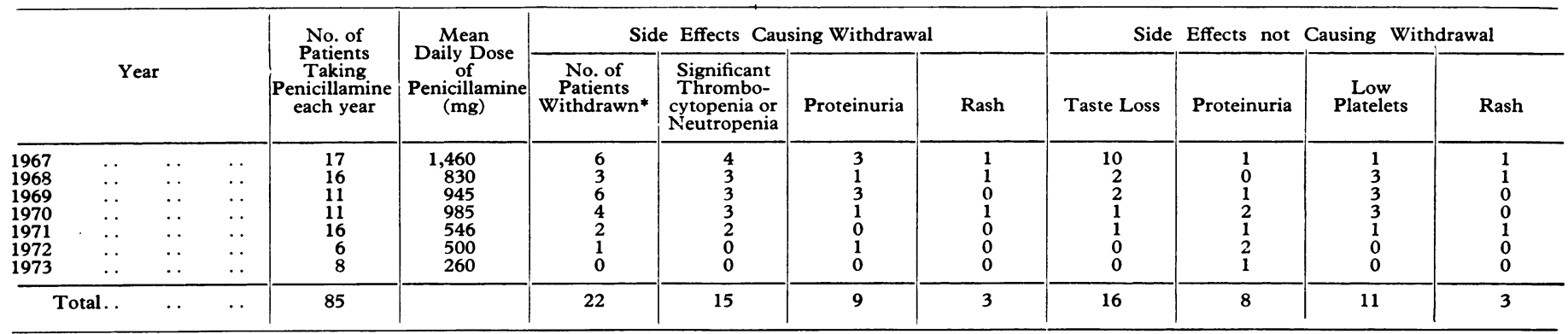

${ }^{*}$ Multiple side effects occurred in some patients.

\section{ADVERSE REACTIONS}

Withdrawal of the patient from penicillamine treatment because of adverse reactions was necessary in many patients at first when large doses were given. Later, as maintenance doses were progressively reduced, the number of withdrawals because of side effects and the incidence of most adverse reactions fell noticeably (table VIII). We have seen no cases of agranulocytosis, aplastic anaemia, or severe thrombocytopenia recently despite our increasing use of the drug, though all of these were seen during the first few years, with one death.

\section{Discussion}

Undoubtedly pencillamine is an effective antirheumatoid drug, though how it acts is unknown. Nevertheless, rash, loss of taste, nausea, vomiting, and anorexia may all occur, and proteinuria occurs particularly often. Jaffe (1970) regards the effect of penicillamine on the kidney as its greatest drawback.

We are less concerned about the renal disorder, which appears to be the result of immune complex nephritis, than about the depression of bone marrow, which is sometimes lethal. Unless proteinuria becomes very heavy $(2 \mathrm{~g} /$ day $)$ we do not discontinue penicillamine. Platelet counts below $100,000 \mathrm{~cm}^{3}$ we regard as reason for withdrawing penicillamine, and we do not make more than one further attempt to reintroduce the drug after recovery. Our use of lower daily doses of penicillamine than those used in the multicentre trial and elsewhere is the chief reason for making this report, for we believe that the incidence of side effects will be much lower with no loss of therapeutic effect if low maintenance doses are aimed at.

Penicillamine should be started at the lowest convenient dose -one capsule of penicillamine hydrochloride daily. The dose should not be increased until after four weeks, when a further capsule daily may be added. A third capsule may be added after a similar interval. Many patients respond to this dose, but if they do not the dose may be increased at the same rate. Throughout treatment the urine should be tested for proteinuria and platelet and white cell counts made before each change of dose and at least monthly.

A controlled trial of penicillamine in early but active rheumatoid disease is now to be undertaken at several centres to see whether it can prevent deterioration in long-term use.

We are grateful to the West Riding Medical Research Trust for financial support and to Dista Products Ltd. for supplies of "Distamine" during the early part of this study and for their foresight in supporting research into the use of a drug which carries no patent protection. Dr. W. H. Lyle has been of the greatest help and encouragement throughout. 


\section{References}

Jaffe, I. A. (1963). Annals of Rheumatic Diseases, 22, 71.

Jaffe, I. A. (1968). Postgraduate Medical fournal, 44, October Supplement, p. 15 .
Jaffe, I. A. (1970). Arthritis and Rheumatism, 13, 436.

Golding, J. R., Wilson, J. V., and Plunkett, T. G. (1968). Postgraduate Medical Fournal, 44, October Supplement, p. 40.

Golding, J. R., Wilson, J. V., and Day, A. T. (1970). Postgraduate Medical Fournal, 46, 599.

Multicentre Trial Group (1973). Lancet, 1, 275.

\title{
Diabetes Mellitus Associated with Epidemic of Infectious Hepatitis in Nigeria
}

\author{
F. C. ADI
}

British Medical fournal, 1974, 1, 183-185

\begin{abstract}
Summary
This report concerns nine cases of diabetes mellitus associated with infectious hepatitis, an epidemic of which swept through eastern Nigeria between 1970 and 1972. All the patients showed the classical symptoms and signs of diabetes. They quickly responded to treatment, and after a few months the diabetes completely disappeared. Corticosteroid-glucose tolerance tests in four patients 12 to 30 months after the remission of their diabetes were normal. Contact with the remaining five patients had been lost a few months after clinical remission of their diabetes. The infectious hepatitis virus may have damaged pancreatic islet cells to cause an acute remittant form of diabetes mellitus.
\end{abstract}

\section{Introduction}

An association between virus infections and diabetes mellitus is well documented in both animals and man. Diabetes mellitus has followed an attack of foot-and-mouth disease in cattle (Pedini et al., 1902; Barboni et al., 1962). The encepinalomyocarditis virus is known to cause pancreatitis and islet tissue damage in mice (Craighead, 1966), in which Coxsackie B4 and B1 virus infections are also known to damage islet tissue (Burch et al., 1971). In man the mumps virus has repeatedly been accused of causing diabetes melitus. Cole (1934) suggested this association in three young diabetics. Meling and Ursing (1958) reported four cases within nine months after an epidemic of mumps in Sweden, when they studied 40 children and two adults. Hinden (1962) found reports of 20 cases and reported a case of his own where severe diabetes mellitus with coma occurred in a 15-month-old child about five weeks after an attack of mumps. Conceivably, therefore, other viruses may damage the islet tissue in the pancreas of man, either temporarily or permanently, to produce clinical diabetes mellitus. Nevertheless, I have been unable to find in the English language medical literature any record of cases of diabetes mellitus associated with infectious hepatitis. This paper reports what must be the unusually large number of nine cases of this association.

\footnotetext{
Department of Medicine, University of Nigeria Teaching Hospital, Enugu, Nigeria

F. C. ADI, M.R.C.P., F.M.C.P. (Nig.), Senior Lecturer
}

\section{Patients}

The nine patients who developed clinical diabetes mellitus after an attack of infectious hepatitis formed part of a group of about 100 cases of the disease seen by me during an epidemic which ravaged the eastern region of Nigeria from 1969 to 1971. It started in the dying stages of the Nigerian civil war, in what was then known as Biafra. An estimated seven to eight million people were crammed into a land space of about 60 by 40 miles ( 80 by $64 \mathrm{~km}$ ) in what must have been the longest siege in recent history. With a breakdown in public health measures and severe overcrowding a classical epidemic of infectious hepatitis swept through a population already severely ravaged by malnutrition and starvation. This background picture might be pertinent in that the nutritional status of the patients may have played some part in the development of the diabetic complication. Nevertheless, the civil war ended in January 1970 and all the cases of diabetes reported in this paper were seen between 1970 and 1972 when nutrition had much improved.

All the nine patients presented with classical symptoms and signs of diabetes mellitus, with marked wasting and dehydration associated with polydipsia and polyuria and in some cases with ketosis. They had glycosuria and a raised fasting blood sugar. They all required insulin followed by oral hypoglycaemic therapy for some months. They then clinically remitted. Five of the cases are not reported in detail here because they defaulted from follow-up, presumably because they remained well.

During follow-up the patients tested their urine with Clinitest tablets daily for the first four to eight weeks and thereafter on three days a week. At first no sugar or glucose powder was allowed but otherwise the normal African diet of mostly carbohydrate foods such as cassava, yam, maize, and rice was unrestricted. The reason for not restricting the diet was that all the patients when first seen were wasted from both the acute liver disease, with its associated marked anorexia for protein and fatty foods, and the diabetes. On a free diet and insulin the diabetes was quickly brought under control and, since the need for insulin progressively diminished, there was no need to interfere with the usual diet. After varying periods of follow-up a modified corticosteroid- ylucose tolerance test (Fajans and Conn, 1954) was done, in which each patient was given a total of $40 \mathrm{mg}$ of prednisolone in four divided doses the day before he reported as an outpatient for a standard glucose-tolerance test. Blood sugars were estimated on capillary blood samples by the method of Folin and Wu.

\section{Case 1}

The patient, a 39-year-old printer, was first seen and admitted to hospital in December 1970 with polyuria, polydipsia, and loss of weight over the preceding two weeks. There was no family history of diabetes mellitus. He was taken ill in September 1970 with severe infectious hepatitis. An epidemic of jaundice had been raging in the 